\title{
Hyper-Consumption to Circular Economy in the United Arab Emirates: Discarding the Disposable and Cherishing the Valuable
}

https://doi.org/10.21272/sec.4(3).33-45.2020.

Jeniece Lusk, ORCID: https://orcid.org/0000-0003-0088-6887

PhD, Department of International Studies, American University of Sharjah, Sharjah, United Arab Emirates

Anne Mook, ORCID: https://orcid.org/0000-0002-7613-7834

PhD, Department of Sociology \& Anthropology, Nazarbayev University, Nur Sultan, Kazakhstan

\begin{abstract}
Overconsumption of resources and consumer items is an important driver for environmental degradation and climate change. Malls, shopping, and conspicuous consumption are deeply ingrained in the local values and the global image of the United Arab Emirates (UAE). The UAE has a diverse and international population with over $85 \%$ expats and numerous opportunities to reduce environmental impact. Increased participation in a circular economy that aims to reduce resource use by recycling materials, reusing products, extending their lifespan, and maintaining their economic value would be an effective strategy to reduce negative environmental impacts. However, little is known about how much and why UAE citizens and residents participate in the circular economy. Therefore, it is important to examine the factors that predict participation in the circular economy in the UAE. To investigate this question, we surveyed $n=163$ undergraduate students at an American-curriculum university in the UAE and explored literature-based explanations as predictors for participation in the circular economy, namely gender, nationality, exposure to circular economy initiatives, efforts to reduce ecological footprints, and sustainable consumer behaviors using index-based negative binomial regression models. We also compare differences in ways and levels of participation in the circular economy between UAE citizens and residents with t-tests. Our results suggest that participation in the circular economy does not emerge from concerted efforts to reduce environmental degradation such as lowering ecological footprint and reducing waste, but rather investments in sustainable and durable items. Emirati citizens are more likely to participate in the circular economy, in particular repairing items, than expat residents. These differences are most likely to be explained by the more stable lifestyles of Emirati citizens as opposed to the more itinerant lifestyles of expat residents.
\end{abstract}

Keywords: sustainability, circular economy, consumption, Middle East, ecological footprint, recycling.

JEL Classification: Q560, Z130.

This work is licensed under a Creative Commons Attribution 4.0 International License.

Cite as: Lusk, J., Mook, A. (2020). Hyper-Consumption to Circular Economy in the United Arab Emirates: Discarding the Disposable and Cherishing the Valuable. SocioEconomic Challenges, 4(3), 33-45. https://doi.org/10.21272/sec.4(3).33-45.2020.

(C) The Authors, 2020. This article is published with open access at Sumy State University.

\section{Introduction}

Despite being a relatively young nation, the United Arab Emirates (UAE) has taken no time to claim its stance as one of the most impressive emerging economies in the world. Before the discovery of oil in the UAE in the early 1960s, the territories making up the Emirates (which had previously been known as the Trucial States) existed on the fruits of trade and pearl diving (Morton, 2016). Decades later the combination of oil revenues, a paternalistic government heavily invested in providing a high standard of living for its citizens, and ambitions to compete with major capitalist nations, have led to a booming retail industry.

Hyperconsumption in the UAE and globally is a driver for economic growth, but the treadmill of production is also a threat to sustainability as our linear economy lifestyles impact the planet negatively throughout all 
phases of the product life cycle (Smart, 2010). In a linear economy, the harvest of raw materials and resources deplenish natural stores, leaving terrains and communities desolate and causing desertification. Then, the manufacturing and distribution phases produce numerous outputs that threaten air, water, land, and biodiversity. As if the irreversible effects of the pollutants produced along this path weren't problematic enough, our "consumption-driven economy", implores us to adhere to product obsolescence, conveniently disposing one object for the next newer, bigger, or better replacement in the market, guaranteeing each item an end-of-life residence in some landfill, reservoir, or ocean. However, the model of reducing and reusing resources in a circular economy model offers realistic green consumption approaches (Bauman, 2007).

A circular economy "aims to reduce resource use by recycling materials and reusing products, extending their lifespan and maintaining their economic value" (European Environment Agency, 2019). For businesses, this includes everything from ecodesign and diminishing product obsolescence from the start to cleaner production and taking responsibility for product end of life (i.e. Schroeder et al., 2018; Chaudhary and Vrat, 2018; Gusmerotti et al., 2018). For consumers, this means changing behaviors and attitudes about consumption, employing practices such as shared use, reuse, repair, or recycling, thereby changing consumption attitudes from ownership to "usership" (European Environmental Agency, 2019). The creation of a circular economy could contribute to climate change mitigation and keep global emissions under the $1.5^{\circ} \mathrm{C}$ goal as established under the Paris Agreement (Schroeder et al., 2018). In addition, such practices could be explicitly useful in achieving at least 21 of the 169 targets of the UN's Sustainable Development Goals. Additional benefits of circular economy practices also include economic savings via the creation of green jobs and increased productivity and efficiency (i.e. European Commission, 2014; Lieder and Rashid, 2016; Schroeder, Anggraeni, and Weber, 2019; Ungerman and Dědková, 2019). Consistent with the literature, we discuss three potential motivations for the participation in a greener and more sustainable circular economy, namely demographic factors, reducing ecological footprint, and sustainable consumerism. After reviewing the relevant literature on these potential motivations for participation in the circular economy, we present our research design, results, and conclusions (including directions for future research and policy recommendations).

\section{Gender, Nationality, and Exposure to Circular Economy Initiatives}

Previous research suggests that while men are often thought to have more knowledge concerning environmental issues (Accury 1990; Gendall and Smith 1995), women are expected to have more concern for the environment (Mohai, 1992; Stern, 1992). Ecofeminists, for example, offer support for this relationship between women and ecology, linking patriarchal exploitation of both women and environment in kind as a binding factor (Warren, 1994). Numerous studies around the world found that women were more oriented towards participating in a sharing economy than their male counterparts (i.e. Lindblom and Lindblom, 2017; Hazen, Mollenkopf, and Wang, 2017; Atlason, Giacalone, \& Parajuly, 2017; Borello et al., 2017). In fact, several feminist scholars argue that patriarchal structures in society are the main obstacle for creating a more sustainable and circular economy (Pla-Julián \& Guevara, 2019; Schroeder Anggraeni, \& Weber, 2019). However, one study conducted in Egypt breaks this pattern and suggests that men may exhibit significantly higher amounts of environmental concern than women (Mostafa, 2007) However, given the diversity of cultures in the Middle East, differences between communities can be expected. For example, Mintz and Kurman (2019) found significant variances in willingness to recycle between Jewish and Muslim-Bedouin residents in the Misgav Regional Council (Galilee region where Jewish and Muslim communities live sideby-side).

Many studies suggest that the higher one's education level, the higher their propensity to participate in sharing models of consumption (i.e. Lindblom and Lindblom, 2015; Liu et al., 2009; Welfens et al., 2016). However, the way education is delivered, especially regarding the circular economy matters. Experiential and hands-on approaches, in particular using games, are shown to be among most effective ways to educate and transform the behaviors of a new generation regarding sustainable behaviors (Dieleman and Huisingh, 2006). Using games as an experimental learning technique to develop ideas to construct a circular economy are shown to be effective with a variety of potential learners including engineering students (Whalen, 2018). These techniques are also effective to communicate the impacts of climate change to a variety of stakeholders and policy makers (van Pelt et al., 2015). Currently, experiential learning is increasingly promoted in university settings with projects such as the sustainable campus initiative and sustainable campus audit (Too and Bajracharya, 2015; Beringer, 2006). Therefore, continuous assessment of access to education and the 
effectiveness of delivery of information is important in developing a path towards a sustainable and circular economy.

\section{Ecological Footprint}

An ecological footprint measures the surface of land and water required for all the goods consumed by a country (Ponthiere, 2009). According to the United Nations (UN) the global material footprint is expanding quickly; in 2000 the global material footprint was 54 billion metric tons and grew to 92 billion metric tons by 2017 (nd). This footprint is expected to more than double from 2017 to 2060, to an estimated 190 billion metric tons. In 2006 the Global Footprint Network found that the UAE had the largest per capita ecological footprint globally, at 11.68 global hectares (World Wildlife Fund, 2006). Responding to this finding, the UAE quickly became one of the first nations to conduct a detailed analysis of its sustainability efforts. The UAE's analysis, the Ecological Footprint Initiative (EFI), found that households contributed overwhelmingly to the UAE footprint at 57\% (Emirates Nature-World Wildlife Fund 2010). Focusing on daily household activities, food $(23 \%)$ and mobility $(21 \%)$ were found to contribute most to the UAE household demand for resources; goods fell close-by at $19 \%$. However, when comparing the proportion of daily household activities by carbon footprint (carbon) consumption-use alone outranked all others (including mobility, food, services, and housing). Thus, one major suggestion resulting from the EFI outcomes was to address the consumption habits and behaviors of residents of the UAE.

Reducing the national ecological footprint in the UAE is no small task. Much of the UAE's appeal as a global tourism and hospitality (and expatriate) hub is the promise of its' ostentatious resource-slurping retail scene; some have gone as far as to describe one of the Emirates, Dubai, as "the Las Vegas of the Middle East" or "the Disneyland of the Middle East" (Willemyns, 2008). Shopping malls are practical in the Gulf because for most of the year, the hot climate drives locals and tourists indoors to air-conditioned spaces. The nation houses the world's biggest mall (The Dubai Mall) and heralds one of the world's largest retail markets. According to Hanieh (2011), the UAE is ranked second worldwide in number of recreational shoppers. As a testament to its residents' buying power, the UAE breaks other retail records, too, including the largest mall in the world by total area, and sixth largest by gross leasable area, and the world's tallest building, the Burj Khalifa (Construction Week, 2010). Additionally, popular entertainment venues and tourist attractions have been integrated into many of the larger malls in the country. The Dubai Mall alone contains a full-size indoor aquarium, direct access to the world's tallest building, and an Olympic-sized ice skating rink along with arcades, fine dining, a haunted house, and more; likewise, the Mall of the Emirates houses a year-round indoor ski resort.

\section{Hyper-Consumerism in the UAE}

Shopping is of utmost importance not only to the UAE economy, but to UAE culture as well. Though one can still find traditional market style souqs throughout the Emirates, shopping malls now dominate as hubs for retail activity, recreation, and entertainment (Klingman, 2016). In a study of consumer-perceived value of shopping malls among a UAE sample, results suggest that consumers receive several types of fulfillment during their shopping activities (El-Adly and Eid, 2015); these include, hedonistic, utilitarian, social interaction, spatial convenience, time convenience, and transaction values. UAE malls in particular are important social centers. Much of the value of these retail activities lies in the consumers' abilities to communicate curated presentations of identity (Kazim, 2018). The possession of desirable items and brand products helps to convey one's position in society. In the UAE status is often conveyed through ability to access the latest designer handbag, driving (or better, yet being driven in) a luxury vehicle, or some other elaborate consumption. With unlimited access to luxury imports paired with disposable incomes, UAE consumers find themselves "continually straining to surround themselves with visible evidence of the superior rank they are claiming" (Packard, 1959). This type of consumption, meant to symbolize class, prestige, and belonging is described as conspicuous consumption, or the consumption of goods to relay one's social status (Veblen, 2007). The distinctions through "taste" (Bourdieu and Nice, 1998) provided by luxury and conspicuous consumption may serve not only as markers displaying one's status but can also be used to gain access to exclusive sectors as well (Daloz, 2013). These types of habits, attitudes, and behaviors may present a challenge to persuading consumers to adopt circular economy practices. In a study of cognitive biases and consumer adoption of a circular economy, researchers outline several factors that may impede on consumer 
behavioral changes; adherence to routines, distrust of remanufactured products, and social pressure are just a few factors that may be barricades to greener consumption (Singh and Giacosa, 2019).

This focus on retail which relies on a "take-make-waste" model is a direct challenge to environmental stability as it strains environmental capacities, and a push for consumption with less destructive addition and withdrawal effects is apparent (Preston, 2012). Environmental consumption, or green consumption, implores producers and consumers to make changes in their behaviors to minimize or mitigate their environmental footprints (Perera, Auger, \& Klein, 2018). Green consumption recognizes the "wasteful and unsustainable" impacts of traditional consumption and challenges of lifestyles organized around overconsumption. Researchers seek to better understand the motivations that influence consumption to offer alternative, sustainable forms of consumption instead (Aitken et al., 2019; Perz et al., 2018).

\section{Methods}

\section{Sample}

To our knowledge, attitudes within the UAE toward circular economy practices and behaviors have yet not been studied. This study employs a quantitative survey research methodology measuring sustainable behaviors and participation in the circular economy. Data was collected using an online survey research design; the study participants were recruited from a student sample enrolled in various international studies courses at an elite American style liberal arts university in the UAE. The online survey was distributed using the Qualtrics (C) Analytic Suite and made available to all students at the university via emails from selected professors via a learning management system in February 2017. The survey remained in the field for 10 days total, collecting a total of 163 responses.

\section{Measures and Operationalization}

The dependent variable used in this study is 'participation in the circular economy,' which is based on an eight-item index constructed from survey questions that asked respondents to indicate whether (no=0, yes $=1$ ) they contribute to the circular economy with specific behaviors that promote reusing, sharing, repairing, refurbishing, and recycling materials to create a closed-loop cycle. Behavioral indexes can be a good strategy to measure participation in the economy (Elia et al., 2017). The eight measures in our index participation in the circular economy include 1) "I am wearing a piece of clothing that has been mended, altered, or repaired"; 2). "One-fourth or more of my clothes are handmade or second hand"; 3). "I use rechargeable batteries whenever I can"; 4). "I make an effort to buy previously owned/refurbished products whenever possible." 5). "I typically keep products as long as possible-until they stop working or break - even if a newer model or upgrade becomes available"; 6). "I avoid disposable items as often as possible (for example, I use a reusable water bottle or bring my own bags to the grocery store)"; 7). "Rather than throw out items, I reuse items"; 8). "Rather than throw out items, I repair items". The total number of ways the respondent participates in the circular economy becomes the final score, ranging from zero to eight (for descriptive statistics of the frequencies for the dependent variable see Table 1).

Table 1. Frequency and Percent Distributions of Number of Ways Respondent Participate in the Circular Economy

\begin{tabular}{|c|c|c|}
\hline$\#$ & Frequency & Percent \\
\hline 0 & 9 & 5.52 \\
\hline 1 & 17 & 10.43 \\
\hline 2 & 20 & 2.27 \\
\hline 3 & 40 & 24.54 \\
\hline 4 & 45 & 10.43 \\
\hline 5 & 17 & 7.98 \\
\hline 6 & 13 & 1.23 \\
\hline 7 & 12 & 0.00 \\
\hline
\end{tabular}

Source: compiled by authors.

We will now introduce the independent variables. To measure gender respondents selected either male or female (male $=0$, female=1), to comply with local Emirati expectations options such as non-binary and transgender were not included. For the nationality variables the respondents could select their country of citizenship from a drop-down box. Given the political tensions between Israel and the Arab world and the 
high number of students that identify as Palestinian, the option Israel was replaced with Palestine. To facilitate comparison, we created dummy variables for the most common nationalities (Emirati, Saudi Arabia, Egypt, and the USA), cultures with a similar cultural background including the Levantine countries (Palestine/Syria/Lebanon/Jordan) and India/Pakistan were grouped together. As most students in the sample should be exposed to the many initiatives of the university's sustainability office to increase participation in the circular economy such as the campaigns to use reusable water bottles an ban plastic on campus as well as well as similar initiatives in various courses and extracurricular activities, we use age as a proxy for exposure to initiatives to participate in the circular economy (younger than $18=0,19=1,20=2,21=3,22$ or older $=4$ ). Finally, as asking directly about social-economic status is often frowned upon, we use type of dwelling as a proxy (apartment $/$ condo/flat $=0$, attached house $=1$, single house $=3$ large house $=4$ ). (for detailed descriptive statistics of the sample see Table 2).

Table 2. Descriptive Statistics on Gender, Nationality, Age, and Type of Dwelling

\begin{tabular}{|c|c|c|}
\hline & Frequency & Percentage \\
\hline \multicolumn{3}{|l|}{ Gender } \\
\hline Male & 53 & 32.52 \\
\hline Female & 110 & 67.48 \\
\hline \multicolumn{3}{|l|}{ Nationality } \\
\hline UAE & 42 & 25.77 \\
\hline Saudi Arabia & 8 & 4.29 \\
\hline Egypt & 21 & 12.88 \\
\hline India/Pakistan & 24 & 14.72 \\
\hline Levantine countries & 28 & 17.18 \\
\hline USA & 8 & 4.91 \\
\hline Other nationality & 45 & 27.61 \\
\hline \multicolumn{3}{|l|}{ Age } \\
\hline 18 or younger & 26 & 15.95 \\
\hline 19 & 37 & 22.70 \\
\hline 20 & 37 & 22.70 \\
\hline 21 & 40 & 24.54 \\
\hline 22 or older & 23 & 14.11 \\
\hline \multicolumn{3}{|l|}{ Type of dwelling } \\
\hline Large single house & 9 & 7.82 \\
\hline Small single house & 18 & 15.65 \\
\hline Attached house/villa & 42 & 36.52 \\
\hline Apartment/condo/flat & 46 & 40.00 \\
\hline
\end{tabular}

Source: compiled by authors.

To measure the independent variables related to personal ecological footprint, we evaluate the respondents' efforts to reduce the use of ecological resources such as electricity, water use, food, and transportation. The survey questions to measure ecological footprint are rederived from an adapted version of the personal ecological footprint calculator from the Institute of Sustainable Energy at Eastern Connecticut State University (Institute of Sustainable Energy, 2017). While this survey was designed for American respondents and the higher temperatures and water scarcity in the UAE will underestimate the actual ecological footprint of the respondent, the survey still measures efforts to reduce ecological footprints well. To avoid overlap with measures related to the circular economy of consumer items, we only use ecological footprint measures related to electricity, water use, food, and transportation. We dropped questions related to shelter and clothes in the original survey as the content is too similar to the dependent variable. Ecological footprints are calculated as follows, the respondent answers 5-9 questions for each of the four categories. For each of the questions the respondent selects the item that best describes his/her everyday behavior. The ecological footprint for energy was measured with the following questions and assigned values for answers. 1). "During the hottest months, our house temperature is __ " (22 degrees Celsius or more $=20,19$ to 22 degrees Celsius $=50,15$ to 18 degrees Celsius $=100$, under 15 degrees Celsius $=150) \quad 2$ ). "I dry clothes outdoor or on an indoor rack" (always $=-50$, sometimes=20, never $=60) .3$ ) "I use an energy efficient refrigerator" (yes=50; $\mathrm{No}=-50)$. 4). "I have a second refrigerator/freezer" (yes=-50; no=0). 5). "We use 3 or more compact fluorescent or LED light bulbs" (yes=50; no=50) 6). "I turn off lights, computer, and television when they aren't in use" (yes=0; no=50). 7). "To cool off, I use __" (air conditioning: car=50; air conditioning: home=100; electric fan=-20; no electric products=-50). 8). "My clothes are usually washed in_" ": (a top loader =100; a front loader=50; a 
laundromat/ coin operate machine $=20$ ). The ecological footprint for water was measured with the following questions and assigned values for answers. 1) "my shower (or bath) on a typical day is": (no shower/no bath=0; short shower 3-4 times a week $=25$; short shower once a day=50). Long shower once a day $=70$, more than one shower per day =90); 2). "I flush the toilet__": (every time I use it=40; sometimes=20). 3) I let the water run when I brush my teeth (yes =20; no =0). 4) I use water saving toilets (yes =20; no =40). 5). I use low-flow showerhead (yes=0; no=-20). The ecological footprint for food was measured with the following questions and assigned values for answers. 1). "On a typical day, I eat __":(meat more than once per day $=600$; meat once per day $=400$; meat a couple times per week $=300$; vegetarian $=200$; vegan=150). 2). "About what proportion of your food comes in packaging?" (all $=100$; some $=30$; none $=0)$. 3). "About what proportion of your food is processed?" (all=100; some=30; none=0). 4). "About what proportion of your food is grown locally and/or organic?" (all=60; some $=30$; none=0). 5). "I compost my fruit/vegetable scraps and peels": (yes=-20; no=60). 6). "On a typical day, I waste": (None of my food=0; 1/4 of my food=25; 1/3 of my food=50;1/2 of my food=100). The ecological footprint for transportation was measured with the following questions and assigned values for answers. 1)." On a typical day, I travel to/on campus by (foot or bike $=0$; public transit=30; private vehicle carpool $=100$; private vehicle alone $=200$ ); 2 ). My vehicle's fuel efficiency is about __ " (more than 13 kilometers/liter=100; 10 to 13 kilometers/liter=100; 7 to 9.9 kilometers/liter=50; less than 7 kilometers/liter=-50). 3). "The time I spend in vehicles on a typical day is ": (no time $=0$; less than half an hour $=40$; half an hour to one hour $=100$; more than one hour=200) 4). "The size of the car in which I travel on a typical day is most similar to": (no car=-20; small=50; medium=100; large (SUV/Van) =200). 5). "Number of cars in our driveway": (no car=-20; less than one car per driver=0; one car per driver=50; more than one car per driver=100; more than 2 cars per driver=200). 6). "Number of flights I take per year": (no flights=0; 1-2 flights=200; more than 2 flights=400). The points correspond to the amount of ecological resources use; the higher the final score the higher the ecological footprint (a high ecological footprint means that the respondent's everyday behavior requires more ecological resources). In our study, we added the points for the categories of water use, electricity, food, and transportation to calculate each respondent's ecological footprint for each of the categories.

Finally, we use a range of questions to measure sustainable consumer behavior. We asked respondents questions about their preference for 'sustainable' products on a four-point Likert-scale ranging from 'doesn't describe me at all $=0$ ' to 'describes me completely $=3$ '. These questions included 1). "I make an effort to buy environmentally friendly products, even if they cost more"; 2). "I make an effort to buy organically grown products, even if they cost more"; 3). "I make an effort to buy from companies with sustainable initiative, even if they cost more". To measure consumption patterns, we asked two questions: "I buy about _ pairs of shoes a year (ranging from 0 to 7 or more)" and "most of my clothes are bought new (no=0, yes=1)", we also inquired about the amount of daily waste by asking "for today all of my garbage would fit into a "(I haven't created any garbage today $=0$. shoebox $=1$, small garbage can $=2$, kitchen garbage can $=3$ ).

\section{Analytical approach}

To test our three explanations for participation in the circular economy, we use a negative binomial regression. Count models such as poison and negative binomial regressions are the most appropriate regression analysis for a multi-item index (Wooldridge, 2010). STATA automatically uses a likelihood-ratio (LR) test to evaluate overdispersion for negative-binomial models; this test was statistically significantly at the $p<0.001$ level, which confirmed overdispersion and suggests that the negative binomial model is the better fit for our data (Karazsia and Van Dulmen, 2008; Gardner et al., 1995). Before accepting the final models, we performed a variance inflation factor (VIF) to control for multicollinearity with the result of 2.15 , which suggests that no corrective measures are necessary (i.e. Robinson and Schumacker, 2009; Miles, 2014). First, we add each theoretical explanation into the negative binomial analyses, then we proceed to combine all models to observe which explanation best predicts participation in the circular economy. Model 1 compares various demographic factors such as gender, age, dwelling, commute to campus, and nationality. This model assesses which demographic factors are associated with participation in the circular economy. Model 2 evaluates personal ecological footprint as a predictor for participation in the circular economy. Model 3 evaluates what consumer behaviors predict participation in the circular economy. Model 4 combines ecological footprint and consumer behavior. Model 5 combines demographic factors and consumer behavior. Model 6 compares all three theoretical explanations. Finally, to further explore why Emirati nationals are more likely to participate in the circular economy than respondents with other nationalities, we perform a student T-test for each of the eight 
behaviors that indicate the levels of participation in the circular economy used in the index constructed for the dependent variable of the negative binomial regression.

\section{Results}

The results are as follows: Model 1, based on gender, nationality, and exposure to circular economy initiatives (analysis of table 3), shows that respondents who are Emirati nationals or citizens of one of the Levantine countries (Palestine, Syria, Lebanon and Jordan) are more likely to participate in the circular economy. This finding was significant at the $\mathrm{p}<0.05$ level). The model accounted for $3 \%$ of the variance.

Table 3. Negative Binomial Regression Predicting Participation in the Circular Economy in the UAE

\begin{tabular}{|c|c|c|c|c|c|c|}
\hline & Model 1 & Model 2 & Model 3 & Model 4 & Model 5 & Model 6 \\
\hline \multicolumn{7}{|l|}{ Demographic factors } \\
\hline Gender & $-.039(.136)$ & & & & $-.029(.127)$ & $-.024(.135)$ \\
\hline Age & $.057(.030)$ & & & & $046(.031)$ & $.031(.032)$ \\
\hline House Type & $-.033(.064)$ & & & & $-.090(.065)$ & $-.056(.067)$ \\
\hline UAE & $.503(.249)^{*}$ & & & & $.622(.259)^{*}$ & $.616(.566)^{*}$ \\
\hline Saudi Arabia & $.481(510)$ & & & & $.238(.538)$ & $.531(.268)$ \\
\hline Egypt & $.684(.510)$ & & & & $.723(.283)^{*}$ & $.534(.298)$ \\
\hline India/Pakistan & $.436(.232)$ & & & & $.504(.248)$ & $429(.255)$ \\
\hline Levantine & $.397(.168)^{*}$ & & & & $.367(.173)^{*}$ & $.278(.178)$ \\
\hline USA & $.157(.278)$ & & & & $.215(.287)$ & $.302(.291)$ \\
\hline Other nationality & $.408(.219)$ & & & & $.455(.229)$ & $.393(.237)$ \\
\hline \multicolumn{7}{|l|}{ Ecological footprint } \\
\hline Transportation & & $-.000(.000)$ & & $-.000(.000)$ & & $-.000(.000)$ \\
\hline Food & & $.001(.000)$ & & $.000(.000)$ & & $-.001(.000)$ \\
\hline Energy use & & $-.001(.000)^{*}$ & & $-.001(.000)$ & & $-.001(.001)$ \\
\hline Water & & $-.004(.001)^{\star *}$ & & $-.003(.002)^{\star \star}$ & & $-.003(.002)$ \\
\hline \multicolumn{7}{|l|}{ Consumer behaviors } \\
\hline Amount of waste & & & $-.048(.052)$ & $-.031(.053)$ & $-.004(.064)$ & $-.005(.068)$ \\
\hline $\begin{array}{l}\text { Consumption of } \\
\text { clothes }\end{array}$ & & & $-.101(.112)$ & $-.046(.114)$ & $-.126(.135)$ & $-.054(.138)$ \\
\hline $\begin{array}{l}\text { Consumption of } \\
\text { shoes }\end{array}$ & & & $-.104(.055)$ & $.044(.059)$ & $-.074(.075)$ & $.016(.081)$ \\
\hline $\begin{array}{l}\text { Buy from sustainable } \\
\text { companies }\end{array}$ & & & $.139(.061)^{*}$ & $.125(.061)^{*}$ & $.180(.075)^{*}$ & $.175(.082)^{*}$ \\
\hline $\begin{array}{l}\text { Buy environmentally } \\
\text { friendly foods }\end{array}$ & & & $.065(.065)$ & $.043(.065)$ & $.008(.086)$ & $-.029(.088)$ \\
\hline Buy organic goods & & & $-.052(.052)$ & $-.055(.052)$ & $-.080(.072)$ & $-.114(.077)$ \\
\hline Constant & $.501(.332)$ & $1.566(.224)^{\star \star \star}$ & $1.291(.320)^{\star * *}$ & $1.59(.505)^{\star \star *}$ & $.606(.547)$ & $1.131(.726)$ \\
\hline $\mathrm{N}$ & 115 & 163 & 161 & 161 & 114 & 114 \\
\hline $\mathrm{R}^{2}$ & 0.03 & 0.04 & 0.04 & 0.07 & 0.07 & 0.09 \\
\hline
\end{tabular}

Source: compiled by authors.

Notes: Coefficients and Standard Errors $+\mathrm{p}<0.10,{ }^{*} \mathrm{p}<0.05, * * \mathrm{p}<0.01, * * * \mathrm{p}<0.001$.

Model 2 explores whether the respondents' ecological footprint predicts participation in the circular economy. The results show a weak negative association between transportation, energy use $(\mathrm{p}<0.05)$, and water use $(\mathrm{p}$ $<0.01$ ). The model accounted for $4 \%$ of the variance. Model 3 investigates how consumer behaviors predict participation in the circular economy. The results show that respondents who try to buy from companies with sustainable initiative, even if they cost more are more likely to participate in the circular economy $(p<0.05)$. This model explains $4 \%$ of the variance. However, buying environmentally friendly goods or organic goods has limited effect on participation in the circular economy. Furthermore, there are no statistically significant findings on consumption patterns or the amount of waste.

Model 4 combines ecological footprint and consumer behavior variables. The model shows that water use continues to be negatively associated with participation in the circular economy $(\mathrm{p}<0.05)$, while buying from companies with sustainable initiatives continues to be a positive predictor $(\mathrm{p}<0.05)$. This model accounts for $7 \%$ of the variance. Model 5 considers demographic factors and consumer behaviors. This model shows that Egyptian nationals $(\mathrm{p}<0.05)$, in addition to Emirati $(\mathrm{p}<0.05)$ and Levantine $(\mathrm{p}<0.05)$ respondents are more likely to participate in the circular economy than other nationalities. Furthermore, buying from companies with sustainability initiatives continues to be a statistically significant predictor $(\mathrm{p}<0.05)$. This model 
accounts for $7 \%$ of the variance. Model 6 evaluates the full model including the demographic factors, ecological footprint, and consumer behavior explanations. According to this final model, Emirati nationals ( $\mathrm{p}$ $<0.05)$ are most likely to participate in the circular economy, while other nationalities are no longer significant predictors. Buying from companies with a sustainability initiative $(\mathrm{p}<0.05)$ remains a significant predictor as well. This model accounts for $9 \%$ of the variance.

Table 4. Itemized T-Test Statistics for Participation in the Circular Economy: Emirati Citizens and Residents

\begin{tabular}{|c|c|c|c|c|c|c|c|}
\hline & \multicolumn{3}{|c|}{ Emirati Citizen } & \multicolumn{3}{|c|}{ Expat } & \multirow{2}{*}{ P-value } \\
\hline & Obs. & Mean & Std. Err. & Obs. & Mean & Std. Err. & \\
\hline $\begin{array}{l}\text { Avoid } \\
\text { disposable }\end{array}$ & 42 & .190 & .061 & 120 & .258 & .040 & 379 \\
\hline $\begin{array}{l}\text { Secondhand } \\
\text { clothes }\end{array}$ & 42 & .119 & .051 & 120 & .125 & .030 & .920 \\
\hline $\begin{array}{l}\text { Mended } \\
\text { clothes }\end{array}$ & 42 & .190 & .061 & 119 & .294 & .041 & .194 \\
\hline Refurbished & 42 & .119 & .051 & 118 & .158 & .033 & .540 \\
\hline Keep products & 42 & .714 & 071 & 121 & .760 & .038 & .556 \\
\hline Reuse & 42 & .761 & .066 & 118 & .694 & .042 & .413 \\
\hline Repair & 42 & .761 & .066 & 120 & .573 & .046 & .031 \\
\hline $\begin{array}{l}\text { Reuse } \\
\text { Batteries }\end{array}$ & 42 & .470 & .077 & 118 & .458 & .046 & .837 \\
\hline
\end{tabular}

Source: compiled by authors.

Now, we want to inspect more closely in what ways Emirati nationals may participate more in the circular economy than other nationalities. Therefore, we perform a Student T-test for each of the measures wherein respondents participate in the circular economy (see Table 4). The results show that Emirati nationals are less likely to avoid disposable items than non-citizens $(\mathrm{NC})$ are (mean $\mathrm{UAE}=.190 \mathrm{vs} \mathrm{NC}=.258$ ). Emiratis are also slightly less likely to buy second-hand clothes (mean $\mathrm{UAE}=.119, \mathrm{NC}=.125$ ), mend or alter clothes (mean $\mathrm{UAE}=.190$, mean $\mathrm{NC}=.294$ ), buy refurbished items (mean $\mathrm{UAE}=.119$, mean $\mathrm{NC}=.158$ ), and keep products until they break (mean $\mathrm{UAE}=.714$, mean $\mathrm{NC}=.760$ ). However, Emirati nationals are more likely to more likely to reuse items (mean $\mathrm{UAE}=.761, \mathrm{NC}=.694$ ), repair items (mean $\mathrm{UAE}=.761, \mathrm{NC}=.573$ ), and reuse batteries (mean $\mathrm{UAE}=.470, \mathrm{NC}=.458$ ). Only repairing items shows a statistically significant difference between the two groups $(\mathrm{p}<0.05)$.

\section{Discussion}

Increased participation in the circular economy has been championed as a potential solution to reduce environmental degradation and mitigate climate change; however popular support varies from country to country. Our data is unique as we know little about participation in the circular economy among residents of the UAE (or the wider Gulf region), a country with $85 \%$ expats and who given their rapid economic growth are amongst the highest consumers in the world. This research focuses specifically on students in the United Arab Emirates, a desert country that has recently jumped on the bandwagon to promote sustainability and innovation.

Our results suggest that respondents' different patterns of participation in the circular economy among residents of the UAE compared to populations studied in other geographical locations. In contradiction with earlier findings in studies in Western countries, in the UAE gender does not seem to influence the likelihood of participating in the circular economy (i.e. Borello et al. 2017; Lindblom and Lindblom 2017). Furthermore, exposure to circular economy initiative does not yet increase the likelihood of participating in the circular economy (Liu et al. 2009; Whalen et al. 2018). However, this result should be taken with caution as the initiatives have significantly intensified the last few years. However, the nationality of the respondent is a significant predictor for participation in the circular economy, especially for Emirati citizens. Furthermore, respondents with a high personal ecological footprint are less likely to participate in the circular economy. This suggests that respondents may be more likely to participate in the circular economy because they keep, reuse, and repair products due to traditional or sentimental value, rather than in interest of saving money or efforts to use environmental resources more sustainably. We find no consistent pattern of efforts to participate in the circular economy driven by sustainable use of resources such as efforts to decrease personal ecological footprint or efforts to reduce consumption and/or waste. We do find, however, that efforts to buy from 
sustainable companies is a statistically significant predictor of participating in the circular economy. This result suggests participation in the circular economy is mostly driven by the desire to invest in durable-quality products that last. Furthermore, investing in sustainable products - particularly so if these products are highend- seems to be part of the Gulf culture of showing off success with the purchase of material goods.

Furthermore, when analyzing the differences between Emirati citizens and expats, it appears that reusing and (especially) repairing items are the most prevalent behaviors related to the circular economy in Emirati citizens. Meanwhile, other behaviors such as avoiding disposable items, mending clothes, and buying refurbished are more common among expats. These findings suggest that Emirati citizens may place high importance on certain items, for example items with monetary value, emotional attachment, or traditional importance. These outcomes make sense given that Emirati citizens tend to have long-standing roots in their cities and villages and are therefore more likely to be able to preserve and keep items, while expats tend to live more itinerant lifestyles.

\section{Further Research}

This study explored different predictors for participating in the circular economy among students at an American-style University in the United Arab Emirates. While on the one hand, we may expect these respondents to be more aware and educated about sustainability efforts, on the other hand, previous studies indicate that less privileged populations have less financial resources to consume and tend to be more concerned with the environment. Therefore, it would be important to explore participation in the circular economy among various populations in the UAE and other Gulf states. Furthermore, the UAE is making significant steps to raise awareness and promote more sustainable lifestyles, especially in the light of the World Expo in Dubai in 2020. Therefore, continuous assessment is recommended to explore how these strategies affect consumption patterns over time. Moreover, understanding how to implement strategies that effectively promote sustainable lifestyles and a circular economy is critical for other predominantly linear economies world-wide.

\section{Policy Recommendations}

As the world is heading towards a Representative Concentration Pathways (RCP) of 8.5, predicting extreme climate change and global temperature rise by about $5-6^{\circ} \mathrm{C}$ by 2100 (NOAA 2020) efforts to curb emissions are critical. Consumption (including water and energy) is the most important driver of climate change (Wysokińska, 2016; Sturman et al., 2017). Therefore, reducing consumption (including waste) is essential to preserve nature and resources. While personal efforts in reducing individual ecological footprints and increased participation in the circular economy are making small contributions to this goal, more rigorous interventions from governments and social institutions are necessary to promote the circular economy as normal environmentalism (Gregson et al. 2015; Moreau et al., 2017), meaning “ environmentalism you don't have to worry about because you just find yourself doing it anyway (Bell \& Ashwood, 2016)." Prominent examples of normal environmentalism that are specific to the circular economy include banning plastics nation-wide, recycling e-waste, promoting a sharing economy. Such government sponsored initiatives have been effective measures to significantly reduce consumption, for example Kenya has recently introduced a selective plastic ban which has improved local environmental conditions (Horvath et al., 2019). Furthermore, companies in China and Mexico work on promising initiatives to make electronic waste reusable ( $\mathrm{Gu}$ et al., 2016; Lepawsky et al., 2017). Therefore, concerted government policies that promote participation in a circular economy could make significant moves toward a reduced use of resources and thereby positive steps towards preventing environmental degradation and mitigating climate change.

The findings of this survey suggest that Emirati students are less likely to reduce the use of disposable products or buy used items than other nationalities are. However, when Emiratis do invest in valuable, traditional, or sentimental items they are more likely to reuse or repair them, rather than replacing them. These findings seem consistent with the glamorous international image of the UAE, where shopping and conspicuous consumption of luxury items is promoted and owning certain products or brands is an important aspect of signaling.

\section{Acknowledgments}

The researchers would like to express their appreciation for the support of the International Studies and Environmental Science departments at the American University of Sharjah. This paper represents the opinion 
of the authors and does not mean to represent the position or opinions of the American University of Sharjah or Nazarbayev University.

Funding: self-funded.

Author Contributions: conceptualization, Anne Mook; data curation, Jeniece Lusk and Anne Mook; formal analysis, Anne Mook; funding acquisition, Jeniece Lusk and Anne Mook; investigation, Jeniece Lusk; methodology, Jeniece Lusk and Anne Mook; project administration, Jeniece Lusk; resources, Jeniece Lusk and Anne Mook; software, Jeniece Lusk; supervision, Jeniece Lusk and Anne Mook; validation, Anne Mook; visualization, Anne Mook; writing - original draft, Jeniece Lusk and Anne Mook; writing - review \& editing, Jeniece Lusk and Anne Mook.

\section{References}

1. Accury, T. (1990). Environmental attitudes and environmental knowledge. Human Organization, 49, 300-304. Available at: https://doi.org/10.17730/humo.49.4.y6135676n433r880.

2. Aitken, R., Watkins, L., \& Kemp, S. (2019). Envisioning a sustainable consumption future. Young Consumers, 20(4), 299-313. Available at: http://dx.doi.org/10.1108/YC-12-2018-0905.

3. Atlason, R. S., Giacalone, D., \& Parajuly, K. (2017). Product design in the circular economy: Users' perception of end-of-life scenarios for electrical and electronic appliances. Journal of Cleaner Production, 168, 10591069. Available at: https://doi.org/10.1016/j.jclepro.2017.09.082.

4. Bauman, Z. (2007). Consuming life. Cambride: Polity Press.

5. Bell, M. M., \& Ashwood, L. L. (2015). An invitation to environmental sociology. Sage Publications. Available at: https://www.worldcat.org/title/invitation-to-environmental-sociology/oclc/919303264.

6. Beringer, A. (2006). Campus sustainability audit research in Atlantic Canada: pioneering the campus sustainability assessment framework. International Journal of Sustainability in Higher Education, 7 (4), 437455. DOI: $10.1108 / 14676370610702235$.

7. Borrello, M., Caracciolo, F., Lombardi, A., Pascucci, S., \& Cembalo, L. (2017). Consumers' perspective on circular economy strategy for reducing food waste. Sustainability, 9(1), 141. Available at: https://doi.org/10.3390/su9010141.

8. Bourdieu, P., Nice, R. (1998). Distinction: A social critique of the judgement of taste. London: Routledge. Available at: chromeextension://ohfgljdgelakfkefopgklcohadegdpif/https://monoskop.org/images/e/e0/Pierre_Bourdieu_Distinctio n A Social Critique of the Judgement of Taste 1984.pdf.

9. Charonis, G. (2012). Degrowth, steady state economics and the circular economy: three distinct yet increasingly converging alternative discourses to economic growth for achieving environmental sustainability and social equity. In World Economic Association Sustainability Conference. Available at: https://sustainabilityconference2012.weaconferences.net/papers/degrowth-steady-state-economics-and-thecircular-economy-three-distinct-yet-increasingly-converging-alternative-discourses-to-economic-growth-forachieving-environmental-sustainability-and-social-eq/.

10. Chaudhary, K., \& Vrat, P. (2018). Circular economy model of gold recovery from cell phones using system dynamics approach: a case study of India. Environment, Development and Sustainability, 22(1), 173-200. DOI: 10.1007/s10668-018-0189-9.

11. Construction Week Online. (27 September 2010). Top 10 construction world record holders. Available at: https://www.constructionweekonline.com/article-9044-top-10-construction-world-record-holders.

12. Daloz, J. (2013). Rethinking social distinction. Basingstoke: Palgrave McMillan. Available at: https://www.palgrave.com/gp/book/9780230300354.

13. Dieleman, H., \& Huisingh, D. (2006). Games by which to learn and teach about sustainable development: exploring the relevance of games and experiential learning for sustainability. Journal of Cleaner Production, 14(9-11), 837-847. Available at: https://doi.org/10.1016/j.jclepro.2005.11.031.

14. D'raven, L., Pasha-Zaidi, N. (2016). Using the PERMA model in the United Arab Emirates. Social indicators research, 125 (3), 905-933. Available at: https://doi.org/10.1007/s11205-015-0866-0.

15. El-Adly, M., and Eid, R. (2015). Measuring the Perceived Value of malls in a non-Western context: The case of the UAE. International journal of retail \& distribution management, 43(9), 849-869. DOI: 10.1108/IJRDM04-2014-0045.

16. Elia, V., Gnoni, M. G., \& Tornese, F. (2017). Measuring circular economy strategies through index methods: 
A critical analysis. Journal of Cleaner Production, 142, 2741-2751. DOI: 10.1016/j.jclepro.2016.10.196.

17. Emirates Nature- World Wildlife Fund (2010). The UAE ecological footprint initiative: summary report 20072010). Retrieved from http://awsassets.panda.org/downloads/en final report ecological footprint.pdf.

18. Esposito, M., Tse, T., \& Soufani, K. (2017). Is the circular economy a new fast-expanding market?. Thunderbird International Business Review, 59(1), 9-14. Available at: https://doi.org/10.1002/tie.21764.

19. European Environment Agency. (2019). Paving the way for a circular economy: Insights on status and potentials. Available at: https://www.eea.europa.eu/publications/circular-economy-in-europe-insights. DOI: $10.2800 / 383390$.

20. European Commission. (2014). Communication from the Commission to the European Parliament, the Council, the European Economic and Social Committee and the Committee of the Regions Towards a Circular Economy: A Zero Waste Programme for Europe. European Commission, Available at: http://eurlex. europa. eu/resource. html.

21. Gardner, W., Mulvey, E. P., \& Shaw, E. C. (1995). Regression analyses of counts and rates: Poisson, overdispersed Poisson, and negative binomial models. Psychological bulletin, 118(3), 392. Available at: https://doi.org/10.1037/0033-2909.118.3.392.

22. Ganivet, E. (2019). Growth in human population and consumption both need to be addressed to reach an ecologically sustainable future. Environment, Development and Sustainability, 1-20. Available at: https://doi.org/10.1007/s10668-019-00446-w.

23. Gendall, P. \& Smith, T. (1995). Knowledge of scientific and environmental facts: a comparison of six countries. Marketing bulletin, 6, 65-73. Available at: http://marketing-bulletin.massey.ac.nz/.

24. Gregson, N., Crang, M., Fuller, S., \& Holmes, H. (2015). Interrogating the circular economy: the moral economy of resource recovery in the EU. Economy and Society, 44(3), 218-243. Available at: https://doi.org/10.1080/03085147.2015.1013353.

25. Gu, Y., Wu, Y., Xu, M., Mu, X., \& Zuo, T. (2016). Waste electrical and electronic equipment (WEEE) recycling for a sustainable resource supply in the electronics industry in China. Journal of Cleaner Production, 127, 331-338. Available at: http://dx.doi.org/10.1016/j.jclepro.2016.04.041.

26. Gusmerotti, N. M., Corsini, F., Borghini, A., \& Frey, M. (2018). Assessing the role of preparation for reuse in waste-prevention strategies by analytical hierarchical process: suggestions for an optimal implementation in waste management supply chain. Environment, Development and Sustainability, 21(6), 2773-2792. DOI: 10.1007/s10668-018-0160-9.

27. Hanieh, A. (2011). Capitalism and class in the Gulf Arab states. (1st ed.). New York: Palgrave Macmillan. Available at: https://www.palgrave.com/gp/book/9780230110779.

28. Hazen, B. T., Mollenkopf, D. A., \& Wang, Y. (2017). Remanufacturing for the circular economy: An examination of consumer switching behavior. Business Strategy and the Environment, 26(4), 451-464. Available at: https://doi.org/10.1002/bse.1929.

29. Horvath, B., Mallinguh, E., \& Fogarassy, C. (2018). Designing business solutions for plastic waste management to enhance circular transitions in Kenya. Sustainability, 10(5), 1664. Available at: https://doi.org/10.3390/su10051664.

30. Institute for Sustainable Energy. (nd). Ecological footprint calculator. Available at: chromeextension://ohfgljdgelakfkefopgklcohadegdpjf/https://www3.epa.gov/airnow/workshop_teachers/calculating carbon_footprint.pdf.

31. Hobson, K., \& Lynch, N. (2016). Diversifying and de-growing the circular economy: Radical social transformation in a resource-scarce world. Futures, 82, 15-25. Available at: https://doi.org/10.1016/j.futures.2016.05.012.

32. Karazsia, B. T., \& Van Dulmen, M. H. (2008). Regression models for count data: Illustrations using longitudinal predictors of childhood injury. Journal of pediatric psychology, 33(10), 1076-1084. DOI: 10.1093/jpepsy/jsn055.

33. Kazim, A. (2018). The emergence of hyper-consumerism in UAE society: A socio-cultural perspective. Perspectives on global development and technology, 17 (4), 353-372. Available at: https://doi.org/10.1163/15691497-12341484.

34. Kirchherr, J., Reike, D., \& Hekkert, M. (2017). Conceptualizing the Circular Economy: An Analysis of 114 Definitions. Resources, Conservation and Recycling, 127, 221-232. Available at: https://doi.org/10.1016/j.resconrec.2017.09.005.

35. Klingmann, A. (2016). The rise of shopping malls within the framework of gulf capitalism. In Lepik, A., Bader, V. S. (Ed.), World of malls: Architectures of consumption, (pp. 175-183). Berlin: Hatje Cantz Verlag. Available 
at: https://www.hatjecantz.de/world-of-malls-6695-1.html.

36. Lepawsky, J., Araujo, E., Davis, J. M., \& Kahhat, R. (2017). Best of two worlds? Towards ethical electronics repair, reuse, repurposing and recycling. Geoforum, 81, 87-99. Available at: https://doi.org/10.1016/j.geoforum.2017.02.007.

37. Lieder, M., \& Rashid, A. (2016). Towards circular economy implementation: a comprehensive review in context of manufacturing industry. Journal of cleaner production, 115, 36-51. Available at: https://doi.org/10.1016/j.jclepro.2015.12.042.

38. Lindblom, A., \& Lindblom, T. (2017). De-ownership orientation and collaborative consumption during turbulent economic times. International journal of consumer studies, 41(4), 431-438. Available at: https://doi.org/10.1111/ijcs.12336.

39. Liu, Q., Li, H. M., Zuo, X. L., Zhang, F. F., \& Wang, L. (2009). A survey and analysis on public awareness and performance for promoting circular economy in China: A case study from Tianjin. Journal of Cleaner Production, 17(2), 265-270. DOI: 10.1016/j.jclepro.2008.06.003.

40. Merli, R., Preziosi, M., \& Acampora, A. (2018). How do scholars approach the circular economy? A systematic literature review. Journal of Cleaner Production, 178, 703-722. Available at: https://doi.org/10.1016/j.jclepro.2017.12.112.

41. Miles, J. (2014). Tolerance and variance inflation factor. Wiley StatsRef: Statistics Reference Online.

42. Mintz, K. K., \& Kurman, J. (2019). A cross-cultural perspective on facilitators of recycling. Environment, Development and Sustainability, 1-17. Available at: https://doi.org/10.1007/s10668-019-00503-4.

43. Mohai, P. (1992). Men, women, and the environment: an examination of the gender gap in environmental concern and activism. Society and Natural Resources, 5, 1-19. Available at: https://doi.org/10.1080/08941929209380772.

44. Moreau, V., Sahakian, M., Van Griethuysen, P., \& Vuille, F. (2017). Coming full circle: why social and institutional dimensions matter for the circular economy. Journal of Industrial Ecology, 21(3), 497-506. Available at: https://doi.org/10.1111/jiec.12598.

45. Morton, M. (2016). Keepers of the golden shore: A history of the United Arab Emirates. London, UK: Reaktion Books. Available at: https://www.goodreads.com/book/show/26153547-keepers-of-the-golden-shore.

46. Mostafa, M. M. (2007). Gender differences in Egyptian consumers' green purchase behaviour: the effects of environmental knowledge, concern and attitude. International Journal of Consumer Studies, 31(3), 220-229. Available at: https://doi.org/10.1111/j.1470-6431.2006.00523.x.

47. Murray, A., Skene, K., \& Haynes, K. (2017). The circular economy: an interdisciplinary exploration of the concept and application in a global context. Journal of Business Ethics, 140(3), 369-380. Available at: https://doi.org/10.1007/s10551-015-2693-2.

48. Packard, V. (1959). The status seekers. New York: David McKay Company. Available at: https://www.worldcat.org/title/status-seekers-an-exploration-of-class-behavior-in-america-and-the-hiddenbarriers-that-affect-you-your-community-your-future/oclc/710676.

49. Perera, C. Auger, P., \& Klein, J. (2018). Green consumption practices among young environmentalists: A practice theory perspective. Journal of business ethics, 152(3), 843-864. DOI: 10.1007/s10551-016-3376-3.

50. Perz, S., Covington, H., Moscoso, J., Griffin, L., Jacobson, G., Leite, F., Mook, A., Overdevest, C., SamuelsJones, T., \& Thomson, R. (2018). Future directions for applications of political economy in environmental and resource sociology: selected research priorities going forward, Environmental Sociology, 4(4), 470-487, DOI: $10.1080 / 23251042.2018 .1446678$.

51. Pitt, J., \& Heinemeyer, C. (2015). Introducing ideas of a circular economy. In Environment, Ethics and Cultures (pp. 245-260). Brill Sense. Available at: https://blogs.helsinki.fi/inventionsforcirculareconomy/circular-economy/.

52. Pla-Julián, I., \& Guevara, S. (2019). Is circular economy the key to transitioning towards sustainable development? Challenges from the perspective of care ethics. Futures, 105, 67-77. DOI: 10.1016/j.futures.2018.09.001.

53. Ponthiere, G. (2009). The ecological footprint: an exhibit at an intergenerational trial?. Environment, development and sustainability, 11(4), 677-694. DOI: 10.1007/s10668-007-9136-x.

54. Preston, F. (2012). A global redesign? Shaping the circular economy. London: Chatham House. Available at: https://www.chathamhouse.org/publications/papers/view/182376.

55. Robinson, C., \& Schumacker, R. E. (2009). Interaction effects: centering, variance inflation factor, and interpretation issues. Multiple Linear Regression Viewpoints, 35(1), 6-11. Available at: chromeextension://ohfgljdgelakfkefopgklcohadegdpjf/http://citeseerx.ist.psu.edu/viewdoc/download?doi=10.1.1.620 
$.5853 \&$ rep $=$ rep $1 \&$ type $=$ pdf.

56. Schroeder, P., Anggraeni, K., \& Weber, U. (2019). The relevance of circular economy practices to the sustainable development goals. Journal of Industrial Ecology, 23(1), 77-95. Available at: https://doi.org/10.1111/jiec.12732.

57. Singh, P., Giacosa, E. (2019). Cognitive biases of consumers as barriers in transition towards circular economy. Management decision, 57(4), pp. 921-936. DOI: 10.1108/MD-08-2018-0951.

58. Smart, B. (2010). Consumer society: Critical issues and Environmental consequences. London: Sage. Available at: https://uk.sagepub.com/en-gb/eur/consumer-society/book232279.

59. Stern, P. (1992). What psychology knows about energy conservation. American psychologist, 47 (10), 12241232. Available http://scholar.google.com/scholar?as_q=Twixst+Cup+and+Lip:+Organizational+Behavior,+Technical+Predi ction+and+Conservation+Practice\&as_authors=Cebon.

60. Sturman, E. D., Dufford, A., Bremser, J., \& Chantel, C. (2017). Status striving and hypercompetitiveness as they relate to overconsumption and climate change. Ecopsychology, 9(1), 44-50. Available at: https://doi.org/10.1089/eco.2016.0027.

61. Too, L., \& Bajracharya, B. (2015). Sustainable campus: engaging the community in sustainability. International Journal of Sustainability in Higher Education. 16 (1), 57-71. DOI: 10.1108/IJSHE-07-2013$\underline{0080}$.

62. Ungerman, O., \& Dědková, J. (2019). Model of the circular economy and its application in business practice. Environment, Development and Sustainability, 1-26. DOI: 10.1007/s10668-019-00351-2.

63. United Arab Emirates Government. (2019). The official guide to living, working, visiting, and investing in the UAE. Available at: https://www.government.ae/\#/.

64. United Nations Development Program. (2019). Human development report. Available at: http://hdr.undp.org/sites/all/themes/hdr_theme/country-notes/ARE.pdf.

65. United Nations Sustainable Development. (nd.). Infographic: responsible consumption and production. Available at: https://www.un.org/sustainabledevelopment/sustainable-consumption-production/.

66. Van Pelt, S. C., Haasnoot, M., Arts, B., Ludwig, F., Swart, R., \& Biesbroek, R. (2015). Communicating climate (change) uncertainties: simulation games as boundary objects. Environmental science \& policy, 45, 41-52. DOI: $10.1016 /$ j.envsci.2014.09.004.

67. Veblen, T. (2007). The theory of the leisure class. NY: Oxford University Press. Available at: chromeextension://ohfgljdgelakfkefopgklcohadegdpjf/http://moglen.law.columbia.edu/LCS/theoryleisureclass.pdf.

68. Warren, K. (1994). Ecological feminism. London: Routlege. Available at: https://www.jstor.org/stable/41301655?seq=1.

69. Welfens, M. J., Nordmann, J., \& Seibt, A. (2016). Drivers and barriers to return and recycling of mobile phones. Case studies of communication and collection campaigns. Journal of cleaner production, 132, 108121. Available at: chromeextension://ohfgljdgelakfkefopgklcohadegdpjf/https://pdfs.semanticscholar.org/42eb/113598f4ef2ec56efad0 54ccb8d8eee0018d.pdf

70. Whalen, K. A., Berlin, C., Ekberg, J., Barletta, I., \& Hammersberg, P. (2018). ‘All they do is win': Lessons learned from use of a serious game for Circular Economy education. Resources, Conservation and Recycling, 135, 335-345. Available at: https://doi.org/10.1016/j.resconrec.2017.06.021.

71. Willemyns, M. (2008). The rapid transformation Emirati managers' values in the United Arab Emirates. In the proceedings of the academy of world business marketing and management development. Available at: https://ro.uow.edu.au/cgi/viewcontent.cgi?article=1173\&context=dubaipapers.

72. Wysokińska, Z. (2016). The "new" environmental policy of the European Union: A path to development of a circular economy and mitigation of the negative effects of climate change. Comparative Economic Research, 19(2), 57-73. Available at: https://doi.org/10.1515/cer-2016-0013.

73. Wooldridge, J. M. (2010). Econometric analysis of cross section and panel data. MIT Press. Available at: chromeextension://ohfgljdgelakfkefopgklcohadegdpjf/https://jrvargas.files.wordpress.com/2011/01/wooldridge_j2002_econometric_analysis_of_cross_section_and_panel_data.pdf.

74. World Wildlife Fund. (2006). Living planet report 2006. Available at: https://d2ouvy59p0dg6k.cloudfront.net/downloads/lpr_living_planet_report_2006.pdf. 